\title{
Communication About Health Information Technology Use Between Patients and Providers
}

\author{
Joy L. Lee, $P h D^{1,2}$ (1) , Susan M. Rawl, $P h D^{3,4}$, Stephanie Dickinson, MS ${ }^{5}$, Evgenia Teal, $M S^{2}$, \\ Layla B. Baker, MBChB ${ }^{2}$, Chen Lyu, MPH', Will L. Tarver, DrPH, MLIS ${ }^{7,8,9}$, and \\ David A. Haggstrom, $M D^{1,3,4,7}$
}

'Indiana University School of Medicinelndianapolis, IN, USA; ${ }^{2}$ Regenstrief Institute, Inc. and Indiana University Center for Health Services and Outcomes Research Indianapolis, IN, USA; ${ }^{3}$ Indiana University School of Nursinglndianapolis, IN, USA; ${ }^{4}$ Indiana University Melvin and Bren Simon Comprehensive Cancer CenterIndianapolis, IN, USA; Indiana University School of Public HealthIndianapolis, IN, USA; Indiana University Center for Survey ResearchIndianapolis, IN, USA; ${ }^{7}$ Indianapolis VA HSR\&D Center for Health Information and CommunicationIndianapolis, IN, USA; ${ }^{7}$ The Ohio State University College of MedicineColumbus, OH, USA; ${ }^{9}$ The Ohio State University Comprehensive Cancer CenterColumbus, $\mathrm{OH}, \mathrm{USA}$.

\begin{abstract}
BACKGROUND: Although growing, the prevalence of the use of health information technology (HIT) by patients to communicate with their providers is not well understood on the population level, nor whether patients are communicating with their providers about their use of HIT.

OBJECTIVE: To understand whether patients are communicating with their providers about HIT use and the patient characteristics associated with the communication.

DESIGN: Cross-sectional, self-administered survey of a sample of patients across the state of Indiana.

PARTICIPANTS: Nine hundred seventy adult participants from across Indiana, $54 \%$ female and $79.5 \%$ white.

MAIN MEASURES: The survey included sections assessing health information-seeking behavior, use of health information technology, and discussions with doctors about the use of HIT.

KEY RESULTS: The survey had a $12 \%$ response rate. Sixty-three percent of respondent reported going to the Internet as the first source when seeking health information, while only $19 \%$ of respondent reported their doctor was their first source. When communicating with doctors electronically, $31 \%$ reported using an electronic health record messaging system, $24 \%$ used email, and $18 \%$ used text messaging. Only 39\% of respondents reported having had any conversation about HIT use with their providers. CONCLUSIONS: There remain many unmet opportunities for patients and providers to communicate about HIT use. More guidance for patients and care teams may both help facilitate these conversations and promote optimal use, such as recommendations to ask simple clarification questions and minimize inefficient, synchronous communication when unnecessary.
\end{abstract}

KEY WORDS: patient-provider communication; patient portal; health information technology

Electronic supplementary material The online version of this article (https://doi.org/10.1007/s11606-020-05903-1) contains supplementary material, which is available to authorized users.

Received November 7, 2019

Accepted May 4, 2020

Published online May 27, 2020
J Gen Intern Med 35(9):2614-20

DOI: $10.1007 / \mathrm{s} 11606-020-05903-1$

(C) Society of General Internal Medicine 2020

\section{BACKGROUND AND SIGNIFICANCE}

Advances in health information technology (HIT) in the last two decades have transformed how patients and their care teams seek and access information, and how they communicate with each other. Many providers now grant patients access to patient portals, which may include access to their electronic health records, as well as the ability to send messages to providers and schedule appointments. As of 2015, $87 \%$ of physician offices had some form of electronic health record system, and $65 \%$ had the capability to exchange electronic secure messages with patients. ${ }^{1}$ However, only $37 \%$ of patients reportedly use patient portals to access their medical records. ${ }^{2}$ Although the use of patient portal has been found to be positively associated with behavioral outcomes such as medication adherence, patient engagement, and patient knowledge, the clinical effects of portal use are mixed. ${ }^{3-5}$ At a population level, the prevalence of the use of HIT for communication, and the types of patients who are most likely to communicate with their care team via HIT, are not well understood. ${ }^{6}$

Patients and their providers have largely navigated health information seeking, and HIT communication channels independently, and without any formal guidance. A lack of patientprovider communication about HIT may result in lower use and unmet patient needs. In this study, we examined patient health information-seeking behavior, as well as the use of HIT to communicate with providers, and the extent that patients talk with their providers about either behavior. Previously, researchers have found that Internet health information seeking can improve the patient-physician relationship if the patient discusses the information with the physician. Current professional guidelines for electronic communication recommend that physicians have in-person discussions with their patients about electronic communication before using 
such technologies. ${ }^{7}$ This is one of few suggested best practices for electronic communication with expert consensus. ${ }^{7}$ Yet the needed in-person communication that lays the groundwork for future use of health information technology may be overlooked in clinical practice. In this study, we sought to understand how patients are communicating with their providers using health information technology, the prevalence of in-person communications about technology use, and what factors are associated with patients communicating with their providers about their use of health information technology.

\section{METHODS}

We conducted a cross-sectional, self-administered survey of a sample of patients from Indiana University Health (IU Health) across the state of Indiana. The study was approved by the Indiana University Institutional Review Board.

\section{Sample Frame}

This survey was conducted as part of an institutional effort to better understand the needs of the population catchment area of the Indiana University Simon Cancer Center (IUSCC), including needs in health information technology use and communication. Survey respondents were adults between the ages of 18 and 75 living in 34 Indiana counties across the state with higher cancer mortality rates than the state average (194.7 to 234.6 deaths per 100,000 people) ${ }^{8}$

\section{Survey Instrument}

The survey included sections assessing health informationseeking behavior, use of health information technology, and sociodemographic characteristics.

Measures. Questions about health information-seeking behavior included the respondents' use of the internet, the first source they turned to in their most recent search for information about health or a medical topic, and their trust in health information sources. The survey also included questions about respondent attitudes about seeking health information. Concerns about seeking health information were assessed with questions regarding the effort required to find needed health information, the degree of frustration experienced while searching for information, concerns about the quality of the information, and whether the information was hard to understand. Use of health information technology included questions about technology platforms respondents used to communicate with their providers. Sociodemographic information included variables assessing age, sex, race, education, employment status, home ownership status, and income. These questions were previously developed for the Health Information National Trends Survey (HINTS). The survey also included novel questions about whether respondents used HIT to communicate with their doctor or a doctor's office in the past year. Respondents were also asked whether they ever talked to their doctor about their use of HIT. The complete text of survey items reported here are included in Appendix 1.

\section{Data Collection}

Data collection occurred in January and February of 2018. The Indiana University Center for Survey Research mailed survey packages to the individuals sampled. The first mailing included the survey instrument, cover letter introducing the study, study information sheet, HIPAA authorization form, a postage-paid and pre-addressed envelope to return the completed survey, and an advance incentive of a $\$ 1$ bill. A postcard reminder followed 2 weeks later. Non-respondents were mailed a second copy of the survey and a reminder letter a month later.

\section{Analysis}

Descriptive statistics were performed on individual sociodemographic characteristics, health information-seeking behavior, and technology use. Multivariable logistic regression models were performed to assess the relationship between communication with doctors about health information technology as the main variable of interest and respondent characteristics, including geographic location (rural/urban), age group, sex, race, education, employment, home ownership, and income. Survey weights were created using the SurveyLogistic procedure (SAS System for Windows version 9.4), which projects data from the sample to estimate rates in the larger population. Weights were used in both the descriptive and regression analyses to account for the stratified sample and oversampling of rural and African-American individuals and to calculate weighted estimates and standard errors for the population.

\section{RESULTS}

A total of 7979 surveys were mailed to eligible participants. The survey had a $12 \%$ response rate, yielding 970 completed surveys that comprised our study sample. Table 1 describes the respondent characteristics, and (statewide) population estimates based on survey weights. The demographic profiles and generalizability of our study sample have been reported elsewhere. ${ }^{9,} 10$ In short, our study sample is largely consistent with estimates of the population. However, we mailed enough surveys to obtain a relatively large absolute number of surveys among rural and AfricanAmerican individuals, two groups among whom we were concerned about the presence of disparities in access to health information technologies. Our study sample also had a higher proportion of older adults and male respondents than population estimates. 
Table 1 Survey Sample Characteristics $(n=970)$

\begin{tabular}{|c|c|c|}
\hline $\begin{array}{l}\text { Patient } \\
\text { characteristics }\end{array}$ & $\begin{array}{l}\text { Survey sample } n \\
(\%)\end{array}$ & $\begin{array}{l}\text { Population estimates } \\
n(\%)\end{array}$ \\
\hline \multicolumn{3}{|l|}{ Age group } \\
\hline $18-34$ & $105(10 \%)$ & $87,683(29 \%)$ \\
\hline $35-49$ & $130(13 \%)$ & $72,122(24 \%)$ \\
\hline $50-64$ & $380(39 \%)$ & $80,769(27 \%)$ \\
\hline $65+$ & $355(37 \%)$ & $63,514(21 \%)$ \\
\hline \multicolumn{3}{|l|}{ Sex } \\
\hline Male & $448(46 \%)$ & $115,100(38 \%)$ \\
\hline Female & $552(54 \%)$ & $188,989(62 \%)$ \\
\hline \multicolumn{3}{|l|}{ Race } \\
\hline African-American & $192(20 \%)$ & $44,084(15 \%)$ \\
\hline White & $743(80 \%)$ & $248,047(82 \%)$ \\
\hline Other & $35(4 \%)$ & $11,958(4 \%)$ \\
\hline \multicolumn{3}{|l|}{ Rural/urban status } \\
\hline Rural & $523(54 \%)$ & $28,702(9 \%)$ \\
\hline \multicolumn{3}{|l|}{ Education } \\
\hline $\begin{array}{l}<\text { High school } \\
\text { (reference) }\end{array}$ & $71(8 \%)$ & $16,169(6 \%)$ \\
\hline High school graduate & $260(28 \%)$ & $60,700(21 \%)$ \\
\hline $\begin{array}{l}\text { Some college/voc } \\
\text { school }\end{array}$ & $253(28 \%)$ & $69,447(24 \%)$ \\
\hline $\begin{array}{l}\text { College grad or } \\
\text { higher }\end{array}$ & $332(36 \%)$ & $143,630(50 \%)$ \\
\hline \multicolumn{3}{|l|}{ Self-reported health } \\
\hline Excellent/very good & $277(29 \%)$ & $112,520(37 \%)$ \\
\hline Good & $408(42 \%)$ & $113,963(37 \%)$ \\
\hline Fair/poor & $282(29 \%)$ & $77,503(25 \%)$ \\
\hline \multicolumn{3}{|l|}{ Employed } \\
\hline Yes & $369(41 \%)$ & $156,328(55 \%)$ \\
\hline No & $225(25 \%)$ & $74,437(26 \%)$ \\
\hline Retired & $303(34 \%)$ & $52,419(19 \%)$ \\
\hline \multicolumn{3}{|l|}{ Own home } \\
\hline Yes & $638(68 \%)$ & $171,009(58 \%)$ \\
\hline No & $295(32 \%)$ & $122,356(42 \%)$ \\
\hline \multicolumn{3}{|l|}{ Income } \\
\hline$\$ 0-19,999$ & $177(21 \%)$ & $56,817(20 \%)$ \\
\hline$\$ 20,000-49,999$ & $268(31 \%)$ & $64,182(23 \%)$ \\
\hline$\$ 50,000-99,999$ & $277(32 \%)$ & $81,823(29 \%)$ \\
\hline $\begin{array}{l}\$ 100,000+ \\
\text { (reference) }\end{array}$ & $143(17 \%)$ & $78,841(28 \%)$ \\
\hline \multicolumn{3}{|l|}{ Broadband } \\
\hline Yes & $321(42 \%)$ & $111,375(46 \%)$ \\
\hline No & $444(58 \%)$ & $133,009(54 \%)$ \\
\hline
\end{tabular}

\section{Patient Use of Health Information Technology}

Health Information Source. The majority of respondents $(63 \%)$ reported going to the Internet as the first source they turn to when seeking health information. Doctors (19\%) were the second source of information patients most often used first; family was a distant third most often source $(5 \%)$. The remaining sources were used first less than $5 \%$ of the time, including, books (4\%), brochures $(3 \%)$, social media (1\%), and magazines $(1 \%)$.

\section{Health Information Technology as a Communication Tool.}

Figure 1 illustrates what the types of HIT platforms respondents were used for electronic communication. Among this cohort of adult patients in Indiana, 31\% reported using an electronic health record messaging (i.e., patient portal) system "to communicate with their doctor or a doctor's office." Email (24\%) and texts $(18 \%)$ were the next most frequently used HIT platform for patient-provider communication. Video
(2.5\%) and social media (1.8\%) were used, but rarely. More than half of respondents (53\%) reported using no HIT platform to communicate with their doctors in the last year.

Prevalence of Health Information Technology Platform Use To Communicate with Providers. Figure 2 illustrates how often respondents talk to their providers about their use of HIT and the topics discussed. Only $21 \%$ of all patients reported having had a conversation about electronic communication (e.g., discussed using secure messaging to communicate). The $47 \%$ of respondents who used electronic communication tools at all were more likely to have discussed HIT use with their providers (42\%) than non-users (58\%).

Respondents with higher levels of education were more likely to speak to their doctors about electronic communication (Table 2). Female sex and having trust in the Internet, were also significantly associated with speaking to doctors about electronic communication. Notably, geography, race, and income were not found to be associated with speaking to doctors. In the adjusted models, female sex and education were no longer significant factors. Having trust in the internet remained significantly associated with talking to doctors about electronic communication.

\section{DISCUSSION}

Our findings enable researchers, public health officers, and health system leaders to understand how a broad range of patients are using health information technology to communicate with their providers across both urban and rural communities in the state of Indiana. We found that the majority of respondents $(63 \%)$ turned to the internet as their first source for health information and that $47 \%$ had used some type of HIT platform to communicate with their providers - most often through electronic health record portals ("secure messaging"). Our findings on health information sources are similar to what has been observed in national samples, including the Health Information National Trends Survey. In 2012, 70\% of adults who are online use the Internet as their first source for health information, and while $19 \%$ have e-mailed health care providers. ${ }^{11}$ Subsequent surveys of national samples, as well as those focused on specific, diverse, urban, and rural populations have confirmed the Internet and healthcare providers as the two main sources of health information for most patients. ${ }^{12-15}$ Although being of younger and being more educated were associated with seeking health information online, the preference for the Internet and providers as the first sources of health information was consistent across age groups. Rutten et al. found that younger patients, and patients with higher income, were less likely to access health information online without frustration. ${ }^{16}$ 


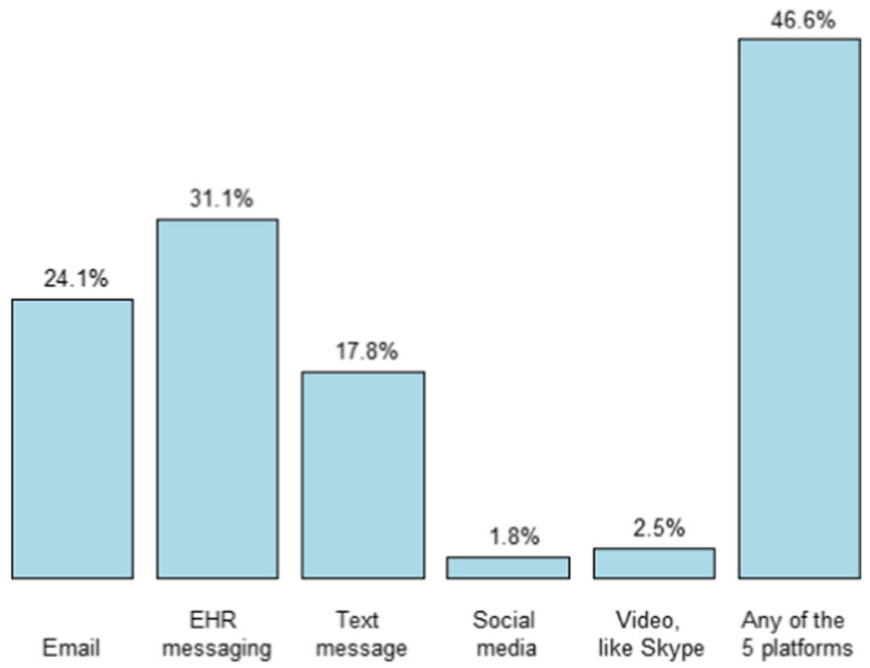

Fig. 1 HIT platforms used for electronic communication.

We also found that $39 \%$ of participants have discussed their use of health information technology with their providers. In an earlier survey, Lee et al. sampled an online cohort of CVS Health users found higher rates of patient reported use of email (37\%) and social media (18\%) to communicate with providers; the survey did not inquire about secure messaging. Differences between the two surveys may be due to temporal changes, or differences in the survey population. At the time of the survey in 2013, secure messaging and electronic health records were less commonly available to patients. ${ }^{17}$ It is possible that as the use of secure messaging has become more prevalent, patients have less interest in, or need for, other channels of communication with their providers, such as email and social media. Nonetheless, our observation that $47 \%$ of respondents who had communicated with their providers using some type of HIT demonstrate widespread patient interest in accessing their providers electronically. The persistence of electronic communication platforms other than secure messaging is demonstrated by the finding that $24 \%$ of respondents reported that they had used email, $18 \%$ used text messaging, and $2 \%$ used social media to communicate with their providers. ${ }^{18}$ That patients still use them point to features or needs unmet by secure messaging.

Our analysis found that identifying as female and having higher education attainment, are positively associated with talking to providers about HIT use. Trust in the internet as a source of health information (versus thus who did not trust the information at all) was also positively associated. These variables may characterize patients who have better access to healthcare providers, or health information. ${ }^{19-21}$ Importantly, patients with access to providers are more likely to experience positive health care communication. ${ }^{22}$ Similarly, Dalton et al. found that patients of higher income, education, and trust in their providers were more likely to perceive patient-provider communication favorably. ${ }^{23}$ It may be that patients who experience more positive communication are more likely to communicate with their providers. Notably, we did not observe any racial, geographic, or income

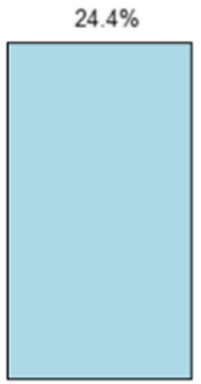

Health information from the internet

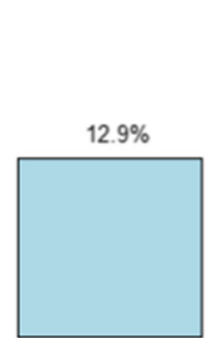

Sources of health information from the internet

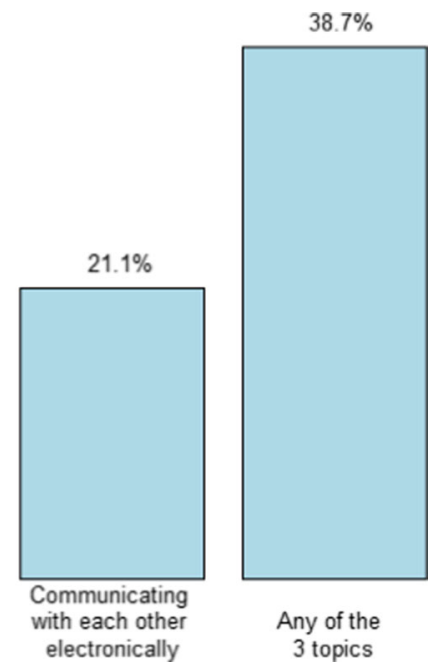

Fig. 2 Topics of communication with providers about HIT use. 
Table 2 Patient Characteristics Associated with Any Discussion with Providers

\begin{tabular}{|c|c|c|c|c|}
\hline & $\begin{array}{l}\text { Odds } \\
\text { ratio }\end{array}$ & $\begin{array}{l}95 \% \\
\text { CI }\end{array}$ & $\begin{array}{l}\text { Adjusted } \\
\text { odds ratio } \\
(n=622)\end{array}$ & $\begin{array}{l}95 \% \\
\text { CI }\end{array}$ \\
\hline \multicolumn{5}{|l|}{ Age group $(\mathrm{ref}=65+)$} \\
\hline $18-34$ & 1.92 & $\begin{array}{l}{[1.03} \\
3.58]\end{array}$ & 1.11 & $\begin{array}{l}{[0.49} \\
2.52]\end{array}$ \\
\hline $35-49$ & 1.72 & $\begin{array}{l}{[0.93} \\
3.20]\end{array}$ & 0.77 & $\begin{array}{l}{[0.34,} \\
1.71]\end{array}$ \\
\hline $50-64$ & 1.30 & $\begin{array}{l}{[0.81} \\
2.08]\end{array}$ & 0.94 & $\begin{array}{l}{[0.50,} \\
1.73]\end{array}$ \\
\hline \multicolumn{5}{|l|}{ Race (ref = other) } \\
\hline Black & 2.74 & $\begin{array}{l}{[0.85} \\
8.86]\end{array}$ & 5.42 & $\begin{array}{l}{[1.18} \\
24.89]\end{array}$ \\
\hline White & 3.50 & $\begin{array}{l}{[1.14} \\
10.70]\end{array}$ & 4.78 & $\begin{array}{l}{[1.22} \\
18.78]\end{array}$ \\
\hline $\begin{array}{l}\text { Sex (female vs } \\
\text { male) }\end{array}$ & $1.85^{* *}$ & $\begin{array}{l}{[1.19,} \\
2.87]\end{array}$ & 1.74 & $\begin{array}{l}{[1.00,} \\
3.06]\end{array}$ \\
\hline \multicolumn{5}{|c|}{ Education $(\text { ref }=<\mathrm{HS})^{\mathrm{a}}$} \\
\hline HS graduate & $1.10 * *$ & $\begin{array}{l}{[0.42,} \\
2.83]\end{array}$ & 1.44 & $\begin{array}{l}{[0.33,} \\
6.32]\end{array}$ \\
\hline Some college & $1.83 * *$ & $\begin{array}{l}{[0.72} \\
4.65]\end{array}$ & 2.26 & $\begin{array}{l}{[0.53,} \\
9.65]\end{array}$ \\
\hline $\begin{array}{l}\text { College grad or } \\
\text { higher }\end{array}$ & $2.94 * *$ & $\begin{array}{l}{[1.22} \\
7.11]\end{array}$ & 2.67 & $\begin{array}{l}{[0.60,} \\
11.82\end{array}$ \\
\hline \multicolumn{5}{|c|}{ Income $($ ref $=\$ 100,000+)$} \\
\hline$\$ 0-19,999$ & 0.57 & $\begin{array}{l}{[0.27} \\
1.21]\end{array}$ & 1.47 & $\begin{array}{l}{[0.50,} \\
4.34]\end{array}$ \\
\hline$\$ 20,000-49,999$ & 0.76 & $\begin{array}{l}{[0.38} \\
1.49]\end{array}$ & 0.88 & $\begin{array}{l}{[0.34,} \\
2.30]\end{array}$ \\
\hline$\$ 50,000-99,999$ & 0.90 & $\begin{array}{l}{[0.47} \\
1.74]\end{array}$ & 1.15 & $\begin{array}{l}{[0.52} \\
2.53]\end{array}$ \\
\hline $\begin{array}{l}\text { Health information- } \\
\text { seeking concerns } \\
\text { (any vs none) }\end{array}$ & 1.48 & $\begin{array}{l}{[0.87} \\
2.51]\end{array}$ & 1.66 & $\begin{array}{l}{[0.90} \\
3.05]\end{array}$ \\
\hline \multicolumn{5}{|c|}{ Self-reported health (ref $=$ fair/poor) } \\
\hline $\begin{array}{l}\text { Excellent/very } \\
\text { good }\end{array}$ & 0.95 & $\begin{array}{l}{[0.52,} \\
1.73]\end{array}$ & 0.64 & $\begin{array}{l}{[0.27,} \\
1.55]\end{array}$ \\
\hline Good & 0.89 & $\begin{array}{l}{[0.51} \\
1.56]\end{array}$ & 0.77 & $\begin{array}{l}{[0.34} \\
1.72]\end{array}$ \\
\hline \multicolumn{5}{|c|}{ Trust in doctor? (ref $=$ a little or not at all) } \\
\hline Some & 2.57 & $\begin{array}{l}{[0.72} \\
9.27]\end{array}$ & 1.29 & $\begin{array}{l}{[0.38,} \\
4.31]\end{array}$ \\
\hline A lot & 2.32 & $\begin{array}{l}{[0.69} \\
7.72]\end{array}$ & 1.06 & $\begin{array}{l}{[0.36,} \\
3.07]\end{array}$ \\
\hline \multicolumn{5}{|c|}{ Trust in Internet? (ref $=$ not at all) } \\
\hline A little & $7.19 * *$ & $\begin{array}{l}{[2.28,} \\
22.60]\end{array}$ & $4.13 *$ & $\begin{array}{l}{[1.43,} \\
11.89]\end{array}$ \\
\hline Some & $7.45 * *$ & $\begin{array}{l}{[2.49,} \\
22.24]\end{array}$ & $4.46^{*}$ & $\begin{array}{l}{[1.69,} \\
11.76]\end{array}$ \\
\hline A lot & $4.85^{* *}$ & $\begin{array}{l}{[1.36,} \\
17.37]\end{array}$ & $3.08^{*}$ & $\begin{array}{l}{[0.82} \\
11.49]\end{array}$ \\
\hline
\end{tabular}

Adjusted odds ratio $=$ odds ratio from model including all variables from Table 2 simultaneously

$* p<0.05, * * p<0.01$

${ }^{a}$ Because education and income were significant across 4 levels, bivariate logistic regression was performed to test each level individually with the reference level $(<$ high school and \$100,000+)

differences among patients who communicate with their providers about HIT use. While our study was adequately powered to detect racial and geographic differences, we may have been underpowered for income differences. It is also possible any relationship that may exist between income and talking to providers is mediated by trust in the internet. In a study examining the "digital divide" and secure messaging, Graetz et al. found that internet access and preference mediated some of the differences in secure messaging use by race and income. $^{24}$
For patients and clinicians, having a shared agenda about using HIT is important to facilitate the online patient-provider relationship and avoid communication errors and harm. In 1999, the Task Force on Guidelines for the Use of ClinicPatient Electronic Mail for the American Medical Informatics Association Internet Working Group established that electronic communication "depends upon negotiation between patient and provider." 25 These negotiations could also be delegated to other members of the care team and may include creating a shared understanding about expected turnaround time, preferences for electronic communication, and types of topics suitable for electronic communication. The lack of verbal and facial cues can make communication through HIT susceptible to misunderstanding, so a shared understanding of how to use electronic communication, created in-person, is recommended by multiple guidelines. ${ }^{25,}{ }^{26}$ In the absence of standard measures of electronic communication quality, having a conversation with patients about their use of electronic communication is one of few clear and actionable practices endorsed by multiple guidelines. ${ }^{7}$ Yet the practice may not be practicable or necessary for every patient, or by every clinician. Not every patient may feel the need to consult their physicians about managing their health with or without HIT. Our findings provide data on instances where a conversation may be warranted - to discuss sources of reliable health information online, to discuss health information online, or to discuss how to communicate using HIT.

The results of this study have important implications for patients, their care team, as well as researchers and policy makers regarding HIT. Many patients perhaps do not realize that they could or should ask providers about how to use HIT in the context of the patient-provider relationship. Our finding that $39 \%$ of patients have discussed some sort of HIT use with their providers suggests that this practice is not uncommon, especially among patients with concerns about finding health information. For providers, the findings suggest that even as patient portal and secure messaging adoption increases, a majority of patients are still not discussing finding health information and communicating using HIT with their providers. Simply asking patients whether they are able to find high-quality information they need online, or are interested in using HIT to facilitate communication, would be a starting point for conversations about HIT use. It may also be possible that these conversations can be initiated by other care team members beside physicians, such as nurses, medical assistants, or other staff who may be tasked with patient portal enrollment. For policy makers, especially of healthcare systems, continued efforts in informing and educating patients about available and institutionally endorsed technology are needed to overcome barriers patients face and to give providers and care team members needed support regarding how to manage secure messaging as well as other forms of communication from patients. More research is needed in understanding effective communication behaviors regarding HIT use and their impact upon patient outcomes. 


\section{Limitations}

The study has several limitations. First, our survey response rate of $12 \%$ was low. Our sample was recruited from a large, statewide, and academic health care system. This sampling method allowed data collection from respondents from throughout the state of Indiana, but generalizability to a population not routinely accessing health services (at least once per year) may be limited. In anticipation of a low response rate, we mailed enough surveys to obtain a relatively large absolute number of survey among rural and African-American individuals, two groups among whom we were concerned about the presence of disparities in HIT use. We did not observe racial or geographic differences in this study. Second, our survey instrument did not ask about other domains relevant to health information seeking and communication about HIT, like respondents' perceptions of the quality of their relationship with their providers, which may be valuable domains to explore in future data collection efforts.

\section{CONCLUSION}

Providers, health care systems, and policy makers benefit from understanding how patients and providers are using HIT to communicate. There remain many unmet opportunities for patients and care team members to communicate about HIT use. Setting expectations and guidelines for electronic communication has the potential to prevent miscommunication and medical errors. ${ }^{7}$ More provider and patient guidance may both help facilitate these conversations and promote optimal use, such as recommendations to ask simple clarification questions and minimize inefficient, synchronous communication (e.g., phone calls, provider visits) when unnecessary. Overall, we found that while nearly half of the patients in the sample (47\%) had used HIT to communicate with their providers, only 39\% had discussed health-related HIT use, and only $21 \%$ had discussed electronic communications with their providers. Clearly, many opportunities remain for broader dissemination of electronic communication tools and wider dissemination of approaches to educate patients in their use.

Acknowledgments: The authors would like to express our gratitude to Rachel Gruber for her comments and copyediting that greatly improved the manuscript.

Corresponding Author: Joy L. Lee, PhD; Regenstrief Institute, Inc. and Indiana University Center for Health Services and Outcomes Research Indianapolis, IN, USA (e-mail: joyllee@iu.edu).

Funding Information NCI Supplement to Indiana University Cancer Center Grant (P30 CA082709-17S6) awarded to Patrick Loehrer; funds received by David Haggstrom and Susan Rawl. Indiana University Melvin and Bren Simon Cancer Center funding awarded to David Haggstrom and Susan Rawl.

\section{Compliance with Ethical Standards:}

Conflict of Interest: The authors declare that they do not have a conflict of interest.

\section{REFERENCES}

1. What is a patient portal? 2017. (Accessed $23 \mathrm{Jul} 2018$, at https://www. healthit.gov/faq/what-patient-portal.)

2. Anthony DL, Campos-Castillo C, Lim PS. Who isn't using patient portals and why? Evidence and implications from a national sample of US adults. Health Aff (Millwood). 2018;37:1948-54.

3. Kruse CS, Bolton $\mathbf{K}$, Freriks G. The effect of patient portals on quality outcomes and its implications to meaningful use: a systematic review. J Med Internet Res. 2015; 17:e44.

4. Han HR, Gleason KT, Sun CA, et al. Using patient portals to improve patient outcomes: systematic review. JMIR Hum Factors. 2019;6:e15038.

5. Coughlin SS, Prochaska JJ, Williams LB, et al. Patient web portals, disease management, and primary prevention. Risk Manag Healthc Policy. 2017; 10:33-40.

6. Fraccaro $\mathbf{P}$, Vigo $\mathbf{M}$, Balatsoukas $\mathbf{P}$, Buchan $\mathbf{I E}$, Peek $\mathbf{N}$, van der Veer SN. Patient portal adoption rates: a systematic literature review and meta-analysis. Stud Health Technol Inform. 2017;245:79-83.

7. Lee JL, Matthias MS, Menachemi N, Frankel RM, Weiner M. A critical appraisal of guidelines for electronic communication between patients and clinicians: the need to modernize current recommendations. J Am Med Inform Assoc. 2017.

8. Indiana cancer facts and figures, Table 4, Indiana cancer mortality (death rates) by county, 2008-2012. (Accessed 12 February 2019, at http:// indianacancer.org/wp-content/uploads/2015/05/Indiana-CancerFacts-and-Figures-2015_web.pdf.)

9. Haggstrom DA, Lee $\mathbf{J L}$, Dickinson SL, et al. Rural and urban differences in the adoption of new health information and medical technologies. J Rural Health. 2019;35: 144-54.

10. Rawl SM, Dickinson S, Lee $\mathbf{J L}$, et al. Racial and socioeconomic disparities in cancer-related knowledge, beliefs, and behaviors in Indiana. Cancer Epidemiol Biomarkers Prev. 2018; [In press].

11. Prestin A, Vieux SN, Chou WY. Is online health activity alive and well or flatlining? Findings from 10 years of the Health Information National Trends Survey. J Health Commun. 2015;20:790-8.

12. Haluza D, Naszay M, Stockinger A, Jungwirth D. Digital natives versus digital immigrants: influence of online health information seeking on the doctor-patient relationship. Health Commun. 2017;32:1342-9.

13. Jacobs W, Amuta AO, Jeon KC. Health information seeking in the digita age: an analysis of health information seeking behavior among US adults. Cogent Soc Sci. 2017;3.

14. Khoong EC, Le GM, Hoskote M, Rivadeneira NA, Hiatt RA, Sarkar U. Health information-seeking behaviors and preferences of a diverse, multilingual urban cohort. Med Care. 2019;57(Suppl 6 Suppl 2):S176S83.

15. Tennant B, Stellefson M, Dodd V, et al. eHealth literacy and Web 2.0 health information seeking behaviors among baby boomers and older adults. J Med Internet Res. 2015;17:e70.

16. Finney Rutten LJ, Blake KD, Greenberg-Worisek AJ, Allen SV, Moser RP, Hesse BW. Online health information seeking among US adults: measuring progress toward a healthy people 2020 objective. Public Health Rep 2019;134:617-25.

17. Office-based physician electronic patient engagement capabilities. 2016. at https://dashboard.healthit.gov/quickstats/pages/physicians-viewdownload-transmit-secure-messaging-patient-engagement.php.)

18. Farnan JM, Snyder Sulmasy L, Worster BK, et al. Online medical professionalism: patient and public relationships: policy statement from the American College of Physicians and the Federation of State Medical Boards. Ann Intern Med. 2013;158:620.

19. DeVoe JE, Tillotson CJ, Lesko SE, Wallace LS, Angier H. The case for synergy between a usual source of care and health insurance coverage. J Gen Intern Med. 2011;26:1059-66.

20. DeVoe JE, Tillotson CJ, Wallace LS. Usual source of care as a health insurance substitute for U.S. adults with diabetes? Diabetes Care. 2009:32:983-9.

21. Jones AL, Cochran SD, Leibowitz A, Wells KB, Kominski G, Mays VM. Usual primary care provider characteristics of a patient-centered medical 
home and mental health service use. J Gen Intern Med. 2015;30:182836.

22. DeVoe JE, Wallace LS, Pandhi N, Solotaroff R, Fryer GE, Jr. Comprehending care in a medical home: a usual source of care and patient perceptions about healthcare communication. J Am Board Fam Med. 2008;21:441-50.

23. Dalton AF, Bunton AJ, Cykert $\mathbf{S}$, et al. Patient characteristics associated with favorable perceptions of patient-provider communication in early-stage lung cancer treatment. J Health Commun. 2014;19:53244.

24. Graetz I, Gordon N, Fung V, Hamity C, Reed ME. The digital divide and patient portals: internet access explained differences in patient portal use for secure messaging by age, race, and income. Med Care. 2016;54:7729.
25. Kane B, Sands DZ. Guidelines for the clinical use of electronic mail with patients. J Am Med Inform Assoc. 1997;5:104-11.

26. Makinen MJ. CP guidelines for e-mail correspondence between a doctor and a patient. 2001; Brussels, Belgium: Standing Committee of European Doctors; 2001. p. 0-11.

Publisher's Note: Springer Nature remains neutral with regard to jurisdictional claims in published maps and institutional affiliations. 